\title{
Clinical manifestations and pregnancy outcomes of COVID-19 in indonesian referral hospital in central pandemic area
}

Muhammad Ilham Aldika Akbar, MD, PhD¹, Khanisyah Erza Gumilar, MD', Rino Andriya, MD, Manggala Pasca Wardhana, MD², Pungky Mulawardhana, MD', Jimmy Yanuar Anas, MD, PhD ${ }^{1,2}$, Ernawati, MD, PhD², Muhammad Ardian Cahya Laksana, MD, MH², Gustaaf Dekker, MD, PhD ${ }^{1,3}$

\footnotetext{
${ }^{1}$ Department of Obstetrics and Gynaecology, Airlangga University Hospital, Universitas Airlangga Faculty of Medicine, ${ }^{2}$ Department of Obstetrics and Gynaecology, Faculty of Medicine Dr. Soetomo General Academic Hospital, Surabaya, Indonesia; ${ }^{3}$ Department of Obstetrics and Gynaecology, Lyell McEwin Hospital, University of Adelaide, Adelaide, Australia
}

\section{Objectives}

Data on the clinical manifestations and pregnancy outcomes of pregnant women with COVID-19 are limited, particularly in developing countries. The aim of this study was to analyze the clinical manifestations and pregnancy outcomes in COVID-19 maternal cases in a large referral hospital in Indonesia.

Methods

This study used a prospective cohort design and included all pregnant women with suspected COVID-19. Subjects were divided into COVID-19 and non-COVID-19 groups based on the results of real-time polymerase chain reaction (RT-PCR) for severe acute respiratory syndrome coronavirus 2 . Clinical characteristics, laboratory results, and pregnancy outcomes were compared between the two groups.

Results

Of the 141 suspected maternal cases, 62 cases were COVID-19-confirmed (43.9\%), while 79 suspected cases were negative $(56.1 \%)$. The clinical manifestations and laboratory findings between the two groups were not significantly different $(P>0.05)$. However, the maternal mortality directly caused by COVID-19 was significantly higher than that in the non-COVID-19 group (8.3\% vs. $1.3 \%$; $P=0.044$; odd ratio, $6.91 ; 95 \%$ confidence interval, $0.79-60.81)$.

\section{Conclusion}

The clinical manifestations and laboratory results of suspected pregnant women with positive and negative RT-PCR COVID-19 results were similar. However, within the Indonesian setting, COVID-19 significantly increases the risk of maternal death through both direct and indirect factors.

Keywords: Maternal health; Maternal mortality; Pregnancy

\section{Introduction}

Since the first case of the human coronavirus disease 2019 (COVID-19) was announced in Wuhan (December 31, 2019), the virus has already infected more than 30 million people, causingalmost a million deaths by September 30, 2020 (WHO COVID-19 Dashboard). WHO declared COVID-19 a pandemic disease in March 2020. Being the third most populated country in Asia, Indonesia has become one of the major COVID-19 hotspots in Southeast Asia. Data from the
Received: 2021.04.14. Revised: 2021.05.20. Accepted: 2021.10.10. Corresponding author: Muhammad Ilham Aldika Akbar, MD, PhD Department of Obstetrics and Gynaecology, Airlangga University Hospital, Universitas Airlangga Faculty of Medicine, Sidosermo PDK III no 196, Surabaya 60239, Indonesia

E-mail: dokter_aldi@yahoo.com

https://orcid.org/0000-0002-2003-9282

Articles published in Obstet Gynecol Sci are open-access, distributed under the terms of the Creative Commons Attribution Non-Commercial License (http://creativecommons. org/licenses/by-nc/3.0/) which permits unrestricted non-commercial use, distribution, and reproduction in any medium, provided the original work is properly cited.

Copyright $\odot 2022$ Korean Society of Obstetrics and Gynecology 


\section{Obstetrics \& Gynecology Science}

Vol. 65, No. 1, 2022

Indonesian government (September 21, 2020) showed that the total number of COVID-19 cases has reached $>245,000$, with 9,553 total deaths and 177,000 recovered cases. However, the accuracy of these national data is not certain. The estimation of the COVID-19 case fatality rate in Indonesia is $3.9 \%$. The prevalence of COVID-19 cases in Indonesia has also been increasing sharply, with the average number of confirmed new cases being approximately 4,000-5,000/day since the first confirmed case on March 2, 2020.

Pregnant women with COVID-19 present with unique challenges to the maternal health services in East Java province, particularly in Surabaya. Most smaller and regional hospitals were not prepared to manage COVID-19 cases, mainly due to the lack of facilities and infrastructure, availability of isolation rooms, and personal protective equipment (PPE) [1]. At the beginning of the pandemic, only four referral hospitals in Surabaya were able to handle maternal COVID-19 cases, including the Airlangga University Academic Hospital (RS UNAIR). RS UNAIR, a secondary hospital level, has been appointed as one of the biggest referral COVID-19 Hospitals in Surabaya. We handled the first cases of pregnancy with COVID-19 in mid-April 2020 at the start of this cohort study.

To date, the effect of COVID-19 on pregnancy remains unclear as the data on this population are limited and are mostly based on a few cases. Chen et al. [2] published one of the first reports of COVID-19 during pregnancy through a retrospective study based on the medical records of nine confirmed COVID-19 cases. The study showed similar clinical characteristics of COVID-19 between pregnant and nonpregnant women, with no evidence of intrauterine vertical transmission. Since then, many papers have been published on COVID-19 during pregnancy. However, most of these are based on retrospective medical record reviews or case reports, and most found results similar to the initial case series by Chen et al. [2]. Various systematic reviews published on larger sample sizes, including 108 cases [3], 92 cases [4], 90 cases [5], and 37 cases [6] reported reassuring findings in terms of clinical outcomes.

Based on the data above, this study aimed to analyze the clinical manifestations and pregnancy outcomes (maternalfetal) in a prospective cohort of COVID-19 cases admitted at the RS UNAIR.

\section{Materials and methods}

This was a prospective cohort study of pregnant women with suspected COVID-19 cases seen at the Universitas Airlangga hospital (Surabaya, Indonesia) from April to August 2020. This study was approved by the Ethical Committee of

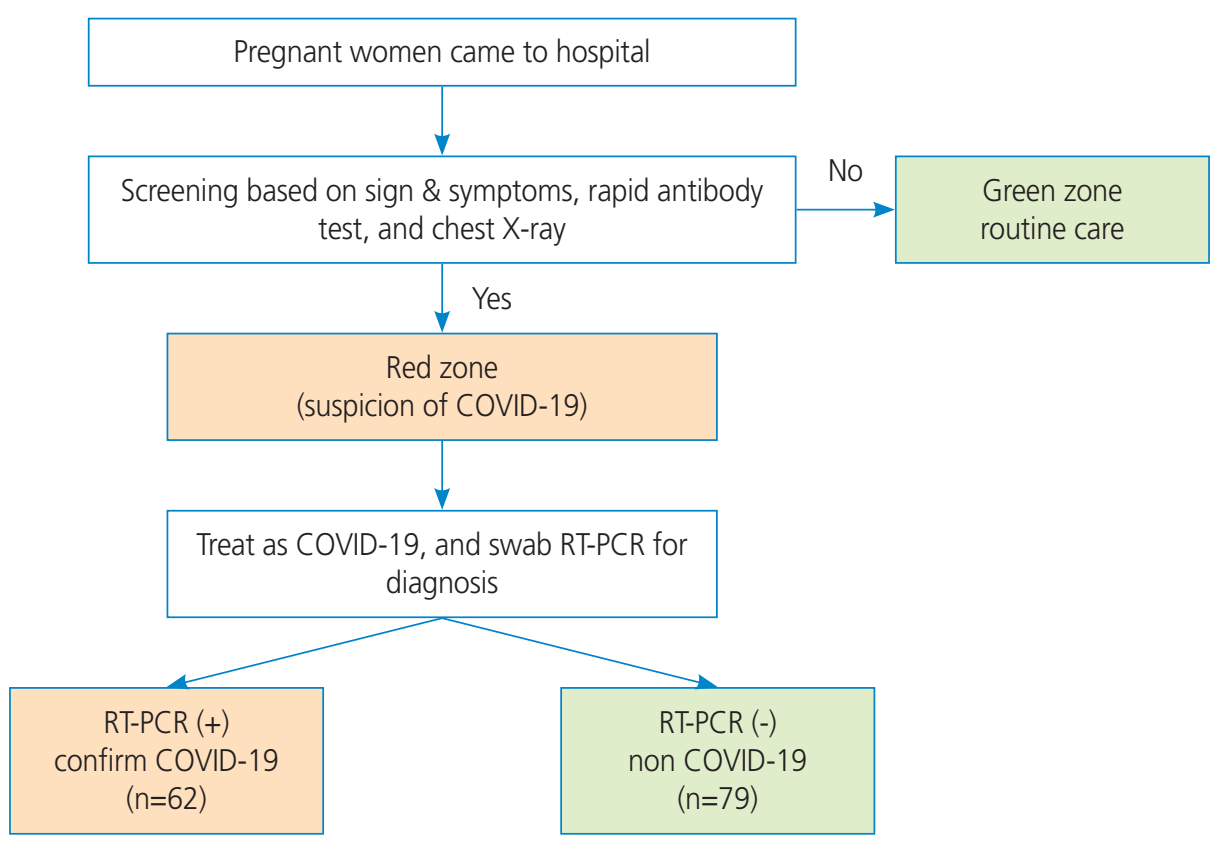

Fig. 1. Algorithm of patient recruitment. RT-PCR, reverse transcription polymerase chain reaction. 


\section{Obstetrics \& Gynecology Science}

the Universitas Airlangga Hospital (Ref. N0:110/KEP/2021). Informed consent was obtained from all the participants before the study began. The subjects were recruited based on our screening methods, which includes the presence of one of the clinical sign-symptoms of COVID 19 (fever, cough, dyspnea, odynophagia, myalgia, or nausea vomiting); a positive rapid antibody COVID-19 test; chest x-ray findings; or an abnormal complete blood count, especially the neutrophi//ymphocyte ratio (NLR) (>5.8) [7]. The study involved all pregnant women with suspected COVID-19 who gave birth at UNAIR Hospital from April 15 until August 31, 2020. All suspected COVID-19 cases were divided into the Covid and non-Covid groups based on the real-time polymerase chain reaction (RT$P C R$ ) result (Fig. 1). RT-PCR samples were collected through nasopharyngeal and oropharyngeal swabs. The patients were then followed up until delivery, and the pregnancy outcome data were collected. The primary outcomes of the study were the clinical manifestations and pregnancy outcomes of COVID-19 during pregnancy. These were divided into maternal outcomes (maternal death, gestational age at delivery, hospital length of stay, pregnancy complications, mode of delivery) and fetal outcomes (preterm delivery rates, birth weight and length, and 1 to 5-minute Apgar scores).

The data were analyzed using SPSS ver. 25 (IBM; Armonk, NY, USA). Descriptive statistics were used to determine the distribution of normality of the numerical variables. The numerical variables with normal distributions (hemoglobin, leukocytes, thrombocytes, and fetal birth weight) were analyzed using independent $t$-test values and are presented as mean \pm standard deviation. Meanwhile, the non-normally distributed numerical variables were analyzed using the MannWhitney test and are presented as a median (interquartile 1-3). The chi-square test was used to analyze the categorical variables. However, the categorical variables that did not fulfill the chi-square test requirement were analyzed using Fischer's exact test (including contact status, myalgia, nausea, vomiting, and maternal outcomes). Statistical significance was defined as $P<0.05$.

\section{Results}

We recruited a total of 141 pregnant women with suspected COVID-19 during the study period, including 62 confirmed cases (43.9\%) and 79 negative cases (56.1\%).

\section{Maternal background}

Regarding the baseline demographics, no differences were identified between the two groups (maternal age, parity, antenatal care frequency, patient entry, referral origin, antenatal care provider, and comorbidities) ( $P>0.05$ ) (Table 1). The only difference was that there were more patients in the COVID-19 group who had a history of contact with sick patients compared to the non-COVID-19 group (6.5\% vs. $0.0 \%$ ). All contact sources were family members confirmed to have COVID-19. Most patients were referred from other hospitals or clinics within the city. No patient had a travel history outside the city/country within 2 weeks before symptom onset.

\section{Clinical manifestation}

The clinical manifestations and laboratory results between the two groups were not statistically different ( $P>0.05$ ) (Table 2). Only $24.2 \%$ of pregnant women in the COVID-19 group had the typical signs and symptoms (mostly cough, fever, and dyspnea). We did not observe anosmia and dysgeusia

Table 1. Maternal background

\begin{tabular}{|c|c|c|c|}
\hline & $\begin{array}{c}\text { Non COVID-19 } \\
(n=79)\end{array}$ & $\begin{array}{c}\text { COVID-19 } \\
(n=62)\end{array}$ & $P$-value \\
\hline Maternal age $^{a)}(y r)$ & $28(7)$ & $28.5(8)$ & 0.118 \\
\hline Parity ${ }^{a)}$ & $1(1-2)$ & $1(2)$ & 0.197 \\
\hline ANC frequency ${ }^{a)}$ & $8(6-9.5)$ & $7.5(6-9)$ & 0.412 \\
\hline \multicolumn{4}{|l|}{ Patients origin } \\
\hline Self appointment & $24(30.4 \%)$ & $17(27.4 \%)$ & 0.825 \\
\hline Referral & $21(26.6 \%)$ & $18(29.0 \%)$ & \\
\hline Free referral & $28(35.4 \%)$ & $23(37.1 \%)$ & \\
\hline Outpatient clinics & $5(6.3 \%)$ & $2(3.2 \%)$ & \\
\hline Other department & $1(1.3 \%)$ & $2(3.2 \%)$ & \\
\hline \multicolumn{4}{|l|}{ ANC provider } \\
\hline No ANC & $0(0.0 \%)$ & $1(1.6 \%)$ & 0.206 \\
\hline $\begin{array}{l}\text { Primary health } \\
\text { care services }\end{array}$ & $2(2.5 \%)$ & $4(6.5 \%)$ & \\
\hline Hospital & $9(11.4 \%)$ & $13(21 \%)$ & \\
\hline Midwifery clinic & $5(6.3 \%)$ & $2(3.2 \%)$ & \\
\hline Mixed & $63(79.7 \%)$ & $42(67.7 \%)$ & \\
\hline \multicolumn{4}{|l|}{ Contact status } \\
\hline No & $79(100.0 \%)$ & $58(93.5 \%)$ & $0.035^{b)}$ \\
\hline Yes & $0(0.0 \%)$ & $4(6.5 \%)$ & \\
\hline
\end{tabular}

ANC, antenatal care; Q, quartile.

${ }^{a}$ Indicates data with non-normal distribution, with a median (Q1-Q3);

${ }^{b)}$ Indicates a significant difference with $P<0.05$. 


\title{
Obstetrics \& Gynecology Science
}

\author{
Vol. 65, No. 1, 2022
}

in any of the cases, which are considered common signs of COVID-19. Furthermore, the mean or median values of the components of the complete blood count (hemoglobin, leukocyte, thrombocyte, neutrophil, lymphocyte, and NLR) were not significantly different between the two groups.

\section{Pregnancy outcomes}

Maternal deaths by all causes in the COVID-19 group were significantly higher than those in the non-COVID-19 group (9.8 vs $1.3 \% ; P=0.044$; odds ratio [OR], $8.29 ; 95 \%$ confidence interval $[\mathrm{Cl}], 0.97-70.84)$. The $\mathrm{OR}$ of maternal death caused by acute respiratory distress syndrome secondary to COVID-19 only was also significantly higher in the COVID-19 group (8.3\% vs. $1.3 \%$; OR, 6.91; $95 \% \mathrm{Cl}, 0.79-60.81)$. The length of stay in the COVID-19 group was also longer than that in the non-COVID-19 group (3 vs. 2 days). The majority of cases in both groups were delivered by cesarean section (63.3\% and $71.7 \%$ ), and approximately $5 \%$ were treated conservatively due to preterm gestation. The three preterm cases of COVID-19 were treated conservatively for threatened preterm labor. The COVID-19 group tended to have a higher rate of pregnancy complications (such as hypertension in pregnancy, arrest of labor, miscarriage, threatened preterm labor, post-date pregnancy, oligohydramnios, and premature rupture of the membrane [PROM]) than the
non-COVID-19 group ( $P=0.130)$. The prevalence of specific pregnancy complications in the non-COVID-19 group vs the COVID-19 group was as follows: hypertension in pregnancy (17.7\% vs. $16.1 \%)$, arrest of labor (6.33\% vs. $4.84 \%)$, and PROM (17.72\% vs. $11.29 \%)$. The perinatal outcomes were not different between the groups in terms of birth weight, length, and Apgar scores. The rate of preterm delivery $<37$ weeks tended to be higher in COVID-19 pregnant women than those without (12.06\% vs. 6.49\%) (Table 3).

\section{Discussion}

The data of this prospective cohort of pregnant with suspected COVID-19 in a major referral hospital in East Java demonstrated a significantly higher risk of maternal death in COVID-19-positive cases. Interestingly, only $24.2 \%$ of the patients confirmed to be COVID-19-positive had signs and symptoms during admission. In other words, the majority of COVID-19 cases on pregnancy were asymptomatic (75.8\%) but were suspected to be positive based on an antibodybased screening test. This is consistent with the findings of a study from New York, which found that 29 out of 33 (87.9\%) pregnant women with confirmed COVID-19 were asymptomatic [8]. Based on these findings, universal screen-

Table 2. Clinical manifestation

\begin{tabular}{|c|c|c|c|}
\hline & Non COVID-19 $(n=79)$ & COVID-19 $(n=62)$ & $P$-value \\
\hline Sign \& symptoms & $19(24.1 \%)$ & $15(24.2 \%)$ & 0.984 \\
\hline Cough & $16(20.3 \%)$ & $12(19.4 \%)$ & 0.894 \\
\hline Fever & $5(6.3 \%)$ & $9(14.5 \%)$ & 0.107 \\
\hline Dyspneu & $6(7.6 \%)$ & $8(12.9 \%)$ & 0.295 \\
\hline Odinophagia & $4(5.1 \%)$ & $3(4.8 \%)$ & 0.951 \\
\hline Myalgia & $0(0.0 \%)$ & $1(1.6 \%)$ & 0.440 \\
\hline Nausea vomitting & $2(2.5 \%)$ & $4(6.5 \%)$ & 0.405 \\
\hline Rapid antibody test & $50(64.9 \%)$ & $40(72.7 \%)$ & 0.343 \\
\hline Hemoglobin ${ }^{\text {a) }}(\mathrm{g} / \mathrm{dL})$ & $11.34 \pm 1.48$ & $10.83 \pm 1.80$ & 0.072 \\
\hline Leucocyte $^{a)}\left(10^{3} / u L\right)$ & $11,270 \pm 3,500$ & $10,552 \pm 5,002$ & 0.327 \\
\hline Trombocyte $^{\text {a) }}\left(10^{3} / \mathrm{uL}\right)$ & $279,835 \pm 83,053$ & $289,306 \pm 80,894$ & 0.504 \\
\hline Neutrophil ${ }^{b)}$ & $76.1(71.05-80.85)$ & $76.6(71.37-83.12)$ & 0.217 \\
\hline Lymphocyte $^{\text {b) }}$ & $15.5(13.05-20.20)$ & $15.8(11.15-20.47)$ & 0.309 \\
\hline$N L R^{b)}$ & $4.88(3.52-6.07)$ & $4.94(3.63-7.78)$ & 0.226 \\
\hline
\end{tabular}

$\mathrm{NLR}$, neutrophil/lymphocyte ratio; SD, standard deviation; Q, quartile.

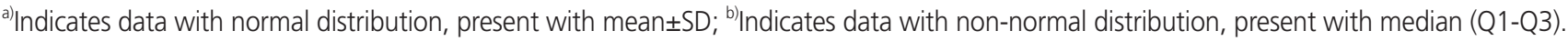




\section{Obstetrics \& Gynecology Science}

Muhammad Ilham Aldika Akbar, et al. COVID-19 in pregnancy

ing for COVID-19 among pregnant women in labor should be performed routinely in areas with high local transmission rates, such as Surabaya [8]. This is in line with the official national recommendations by the POGI (perkumpulan obstetri ginekologi indonesia) and the Royal College of Obstetricians and Gynecology (RCOG) to universal screen all delivering women [9]. Knowledge of the COVID-19 status is important because it determines the place of care, labor/postpartum/ newborn management, the use of PPE, and the availability of isolation rooms. This policy is different from that of other guidelines, such as FIGO, ISUOG, ISIDOG, and RCPI, which recommend screening and diagnosis to be performed selectively in high-risk cases. However, these professional groups acknowledge that the threshold of suspicion indicating a laboratory-based examination should be lowered [10-13]. The clinical signs and symptoms in this study included cough (19.4\%), fever (14.5\%), dyspnea (12.9\%), nausea vomiting (6.5\%), odynophagia (4.8\%), and myalgia (1.6\%). This finding is in line with those of many previous studies $[2,14,15]$.

The significantly higher risk of maternal death $(>8 x)$ in this prospective cohort is in contrast with the findings from the systematic reviews by Zaigham and Andersson [3] and Smith et al. [4], which found no maternal death among a total of 200 pregnant women with COVID-19. Of the six maternal deaths in their cohorts, five were directly related to COVID-19, namely respiratory failure, including three term cases, two preterm cases, and one who was in the 2 nd trimester (17 weeks age of gestation). One case was complicated by se-

Table 3. Maternal and perinatal Outcomes

\begin{tabular}{|c|c|c|c|}
\hline & Non COVID-19 $(n=79)$ & COVID-19 $(n=62)$ & $P$-value \\
\hline \multicolumn{4}{|l|}{ Maternal outcomes } \\
\hline Survive & $76(98.7 \%)$ & $55(90.2 \%)$ & $\begin{array}{c}0.044^{\mathrm{a})} \\
(\mathrm{OR}: 8.29)\end{array}$ \\
\hline Death & $1(1.3 \%)$ & $6(9.8 \%)$ & \\
\hline Gestational ages on arrival (weeks) ${ }^{b}$ & $39(38-40)$ & $39(38-40)$ & 0.885 \\
\hline Gestational ages on delivery (weeks) & $39(38-40)$ & $39(38-39.2)$ & 0.989 \\
\hline Length of stay (days) & $2(2-3)$ & $3(2-3)$ & 0.565 \\
\hline Pregnancy complication & $37(46.8 \%)$ & $37(59.7 \%)$ & 0.130 \\
\hline \multicolumn{4}{|l|}{ Mode of delivery } \\
\hline Vaginal delivery & $25(31.6 \%)$ & $14(23.2 \%)$ & 0.549 \\
\hline Cesarean section & $50(63.3 \%)$ & $43(71.7 \%)$ & \\
\hline Conservative treatments & $4(5.1 \%)$ & $3(5.0 \%)$ & \\
\hline \multicolumn{4}{|l|}{ Fetal outcomes } \\
\hline Stillbirthc) & $3(37.5 \%)$ & $5(62.5 \%)$ & 0.299 \\
\hline $\begin{array}{l}\text { Preterm delivery } \\
<34 \text { weeks }\end{array}$ & $2(2.59 \%)$ & $2(3.45 \%)$ & 0.773 \\
\hline $\begin{array}{l}\text { Preterm delivery } \\
<37 \text { weeks }\end{array}$ & $5(6.49 \%)$ & $7(12.06 \%)$ & 0.250 \\
\hline Low birth weight & $8(47.1 \%)$ & $9(52.9 \%)$ & 0.384 \\
\hline Fetal birth weight $(g)^{d)}$ & $3,074 \pm 544$ & $3,044 \pm 502$ & 0.742 \\
\hline Fetal birth length $(\mathrm{cm})^{b)}$ & $49(48-50)$ & $50(48-50)$ & 0.423 \\
\hline Apgar score 1st minutes ${ }^{b)}$ & $8(7-8)$ & $8(7-8)$ & 0.951 \\
\hline Apgar score 5th minutes ${ }^{\text {b) }}$ & $9(8-9)$ & $9(8-9)$ & 0.653 \\
\hline Abnormal apgar score 1stminutes & $10(13.2 \%)$ & $6(10.5 \%)$ & 0.644 \\
\hline Abnormal apgar score 5th minutes & $4(5.3 \%)$ & $4(7.0 \%)$ & 0.674 \\
\hline
\end{tabular}

$\mathrm{OR}$, odd ratio; SD, standard deviation; $\mathrm{Q}$, quartile.

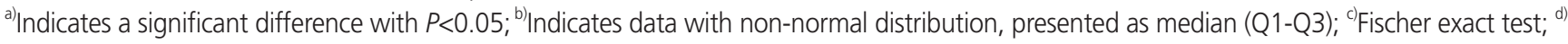
Indicates data with normal distribution, presented as mean \pm SD. 


\title{
Obstetrics \& Gynecology Science
}

\author{
Vol. 65, No. 1, 2022
}

vere preeclampsia requiring cesarean hysterectomy because of severe hemorrhage caused by uterine atony uteri. Following the cesarean hysterectomy, the patient was treated in the intensive care unit with ongoing mechanical ventilation for 10 days before her condition deteriorated slowly. The cause of death in this case was respiratory failure caused by COVID-19, complicated by severe preeclampsia and severe hemorrhage during labor. One maternal death was not directly caused by COVID-19. In our experience, a woman with term pregnancy was referred to our hospital for COVID-19. The delivery was performed in a private midwifery clinic. Unfortunately, fetal anencephaly was diagnosed, and labor was complicated by shoulder dystocia. This patient never received antenatal care during pregnancy, and the COVID-19 test showed a positive result. Referral to our hospital was difficult because many hospitals capable of managing COVID-19 cases were full at that time. After a 1-hour delay, the patient finally arrived at our hospital with the fetal head protruding, but she had already expired due to postpartum hemorrhage. This incident highlights how COVID-19 can also indirectly cause maternal death by delaying the referral or management of emergency obstetric cases. In the non-COVID-19 group, one maternal death occurred due to multiple organ failure caused by an adverse response to the tuberculosis treatment she received.

The rate of maternal complications in the COVID-19 group tended to be higher than that in the non-COVID-19 group (59.7\% vs. $46.8 \%)$. The prevalence of hypertension in pregnancy in the COVID-19 group was not different from that in the non-COVID-19 group (16.1\% vs. $17.7 \%$ ). Narang et al. [16] hypothesized that COVID-19 would enhance the risk of preeclampsia related to endothelial dysfunction and coagulation disorders induced by severe acute respiratory syndrome coronavirus 2. However, in this cohort, we did not find an increase in the risk of preeclampsia.

The high rate of cesarean section in the overall cohort is explained by the fact that, particularly at the beginning of the pandemic, cesarean section was believed to have a lower risk of transmission to the medical staff. In addition, the limited availability of PPEs in many hospitals caused most hospitals to choose cesarean section as the primary method of delivery in order to conserve PPEs [1]. Our national obstetrics gynecology association (POGI) also published the first official recommendation in March 2020, stating that COVID-19-confirmed cases should be delivered through cesarean section [9]. The cesarean section rate in our study was lower than that in systematic reviews of 92 confirm COVID-19 pregnant women (80\%) [4] and 108 cases (92\%) [3]. So far, there is still a lack of clear evidence regarding which delivery method is better in COVID-19 cases, considering maternal and neonatal outcomes [2]. In a recent development, many international guidelines recommended that the method and timing of delivery should be individualized, depending on the clinical status of the patients, gestational age, and the maternal and fetal conditions $[11,13,17]$. Since August 2020, the POGI has published a revision of the guidelines and recommended that the method of delivery should be decided based on the medical and obstetric indications [9]. What remains concerning about the delivery method is the question of whether there is any difference in the transmission of COVID-19 to the medical staff in cesarean section versus vaginal delivery. In a vaginal birth, mothers have to push during the second stage, which is an aerosol-producing procedure that increases the number of droplets in the air and eventually leads to a higher risk of transmission to medical staff or birth attendants. In contrast, this does not occur during cesarean sections. To date, there is still no evidence regarding this matter, so future studies need to address this issue.

Preterm delivery $<37$ weeks tended to be higher in the COVID-19 group than in the non-COVID-19 group, although the difference was not statistically significant. Our rate of preterm delivery rate $<37$ weeks was considerably lower than the reported rate in other systematic reviews $(12.06 \%$ vs. $46.15 \%$ ) [4]. The prevalence of preterm delivery $<34$ weeks in the COVID-19 group was 2.59\%, which was not found in that systematic review [4]. In a multicenter cohort study (not yet published) by the Spanish Obstetrics Emergency Group, it was reported that COVID-19 increased the risk of preterm delivery 2 fold $(\mathrm{OR}, 2.12 ; 95 \% \mathrm{Cl}, 1.32-3.36 ; P=0.002)$ [18]. The increase in the risk of preterm delivery is associated with the cytokine storm in COVID-19, which induces an uncontrolled inflammatory response. Many inflammatory cytokines known to be increased in many cases of preterm birth are also increased in COVID-19, including interleukin (IL)-6, IL$1 \mathrm{~b}$, tumor necrotizing factor-a, granulocyte colony stimulating factors, and macrophages [18]. Compared with the SARS pandemic (2003), our study revealed that the preterm delivery rate was lower. In one of the SARS series involving 12 pregnant women in Hong Kong, the preterm delivery rate was 33.3\% [19]. Besides being caused by the coronavirus, 


\section{Obstetrics \& Gynecology Science}

Muhammad Ilham Aldika Akbar, et al. COVID-19 in pregnancy

two of seven preterm births in this Indonesian series were iatrogenic because of severe preeclampsia.

The stillbirth rate was not significantly higher in COVID-19 patients than in the non-COVID-19 group $(62.5 \%$ vs. $37.5 \%)$. There were five stillbirths in the COVID-19 group, and all were related to maternal death. Of the five stillbirth cases in the COVID-19 group, two were born preterm and had low birth weights. The number of stillbirths in the COVID-19 group in our study was much higher than that in any previous report. In a systematic review of 108 pregnancies with COVID-19, there were only two (1.85\%) stillbirths [3]. In another systematic review that included 92 pregnant women with COVID-19, the perinatal mortality rate was $3.92 \%(2 / 37)$, and all occurred in mothers who expired due to severe COVID-19 [4].

COVID-19 has been shown to be a strong risk factor for maternal death in this study, which may contradict most available reports. The majority of maternal deaths were directly caused by COVID-19 through respiratory failure, though maternal death may also be caused indirectly by delaying the referral and adequate management in the hospital. Intensive and early management is required to prevent maternal death. As such, universal COVID-19 screening in all pregnant women should be performed.

\section{Conflict of interest}

The authors declare no conflicts of interest in this study. This research received no specific grant from any funding agency in the public, commercial, or not-for-profit sectors.

\section{Ethical approval}

This study has been approved by the Ethics Committee of Universitas Airlangga Hospital (Ref. N0:110/KEP/2021).

\section{Patient consent}

All study participants provided written consent to the inclusion of material pertaining to themselves, and all participants were fully anonymized.

\section{Funding information}

None.

\section{Acknowledgments}

We thank our Head and Secretary of the Department, Brahmana Askandar Tjjokroprawiro, and Ashon Saadi for their support in this research. We thank our hospital director and his staff, Prof. Nasronudin, for their support in this study. We thank Erni Rosita Dewi for providing assistance with language corrections. We thank the research team for their remarkable efforts in collecting data for this study. We thank all patients who participated in this study.

\section{References}

1. Ardian M, Laksana C, Habibie PH, Wardhana MP, Erza K. Situation report: maternal health management during COVID-19 pandemic at soetomo general hospital and universitas airlangga academic hospital, surabaya indonesia. Sys Rev Pharm 2020;11:467-71.

2. Chen H, Guo J, Wang C, Luo F, Yu X, Zhang W, et al. Clinical characteristics and intrauterine vertical transmission potential of COVID-19 infection in nine pregnant women: a retrospective review of medical records. Lancet 2020;395:809-15.

3. Zaigham M, Andersson O. Maternal and perinatal outcomes with COVID-19: a systematic review of 108 pregnancies. Acta Obstet Gynecol Scand 2020;99:823-9.

4. Smith V, Seo D, Warty R, Payne O, Salih M, Chin KL, et al. Maternal and neonatal outcomes associated with COVID-19 infection: a systematic review. PLoS One 2020;15:e0234187.

5. Ashraf MA, Keshavarz $P$, Hosseinpour P, Erfani A, Roshanshad $A$, Pourdast $A$, et al. Coronavirus disease 2019 (COVID-19): a systematic review of pregnancy and the possibility of vertical transmission. J Reprod Infertil 2020;21:157-68.

6. Panahi L, Amiri M, Pouy S. Risks of novel coronavirus disease (COVID-19) in pregnancy; a narrative review. Arch Acad Emerg Med 2020;8:e34.

7. Anggraini NWP, Sulistyowati S. Low neutrophil-to- 


\section{Obstetrics \& Gynecology Science}

Vol. 65 , No. 1, 2022

Imphocyte ratio decreases risk of coronavirus disease in pregnant women. Universa Med 2020;39:88-96.

8. Sutton D, Fuchs K, D'Alton M, Goffman D. Universal screening for SARS-CoV-2 in women admitted for delivery. N Engl J Med 2020;382:2163-4.

9. Aziz MA, Chalid MT, Saroyo YB, Budayasa R, Irwinda $R$, Akbar MIA. Rekomendasi penanganan virus corona (COVID-19) pada maternal (Hamil, Bersalin, dan Nifas) [Internet]. Jakarta (IND): POGl; c2020 [cited 2020 Oct 1]. Available from: https://pogi.or.id/publish/wp-content/ uploads/2020/10/Rekomendasi-COVID-Maternal-POGI. pdf.

10. Poon LC, Yang H, Kapur A, Melamed N, Dao B, Divakar $\mathrm{H}$, et al. Global interim guidance on coronavirus disease 2019 (COVID-19) during pregnancy and puerperium from FIGO and allied partners: information for healthcare professionals. Int J Gynaecol Obstet 2020;149:273-86.

11. Donders $F$, Lonnée-Hoffmann R, Tsiakalos A, Mendling W, Martinez de Oliveira J, Judlin P, et al. ISIDOG recommendations concerning COVID-19 and pregnancy. Diagnostics (Basel) 2020;10:243.

12. RCPI loOaG. COVID-19 infection guidance for maternity services [Internet]. Dublin (IRL): Institute of Obstetricians and Gynaecologists; c2020 [cited 2020 Oct 2]. Available from: https://rcpi-live-cdn.s3.amazonaws.com/wpcontent/uploads/2020/04/COVID19-Infection-Guidancefor-Maternity-Services-03_04_2020.pdf.

13. Poon LC, Yang H, Dumont S, Lee JCS, Copel JA, Danneels $L$, et al. ISUOG interim guidance on coronavirus disease 2019 (COVID-19) during pregnancy and puer- perium: information for healthcare professionals - an update. Ultrasound Obstet Gynecol 2020;55:848-62.

14. Allotey J, Stallings E, Bonet M, Yap M, Chatterjee S, Kew $T$, et al. Clinical manifestations, risk factors, and maternal and perinatal outcomes of coronavirus disease 2019 in pregnancy: living systematic review and meta-analysis. BMJ 2020;370:m3320.

15. Lopes de Sousa ÁF, Carvalho HEF, Oliveira LB, Schneider G, Camargo ELS, Watanabe E, et al. Effects of COVID-19 infection during pregnancy and neonatal prognosis: what is the evidence? Int J Environ Res Public Health 2020;17:4176.

16. Narang K, Enninga EAL, Gunaratne MDSK, Ibirogba ER, Trad ATA, Elrefaei A, et al. SARS-CoV-2 infection and COVID-19 during pregnancy: a multidisciplinary review. Mayo Clin Proc 2020;95:1750-65.

17. RANZCOG. COVID-19 and pregnancy in resource-limited environments [Internet]. Melbourneo (AUS): RANZCOG; c2020 [cited 2020 Oct 3]. Available from: https://ranzcog.edu.au/statements-guidelines/covid-19-statement/ resource-limited-environments.

18. Spanish Obstetric Emergency Group, Oscar Martínez Pérez. The association between COVID-19 and preterm delivery: a cohort study with a multivariate analysis. medRxiv 2020 Sep 07 [Epub]. https://doi.org/10.1101/2020. 09.05.20188458.

19. Wong SF, Chow KM, Leung TN, Ng WF, Ng TK, Shek CC, et al. Pregnancy and perinatal outcomes of women with severe acute respiratory syndrome. Am J Obstet Gynecol 2004;191:292-7. 